\title{
An IMD-like pathway mediates both endosymbiont control and host immunity in the cereal weevil Sitophilus spp.
}

\author{
Justin Maire ${ }^{1}$, Carole Vincent-Monégat ${ }^{1}$, Florent Masson ${ }^{1,2}$, Anna Zaidman-Rémy ${ }^{1}$ and Abdelaziz Heddi ${ }^{* *}$ (D)
}

\begin{abstract}
Many insects developing on nutritionally unbalanced diets have evolved symbiotic associations with vertically transmitted intracellular bacteria (endosymbionts) that provide them with metabolic components, thereby improving the host's abilities to thrive on such poor ecological niches. While host-endosymbiont coevolutionary constraints are known to entail massive genomic changes in the microbial partner, host's genomic evolution remains elusive, particularly with regard to the immune system. In the cereal weevil Sitophilus spp., which houses Sodalis pierantonius, endosymbionts are secluded in specialized host cells, the bacteriocytes that group together as an organ, the bacteriome. We previously reported that at standard conditions, the bacteriome highly expresses the coleoptericin A (co/A) antimicrobial peptide (AMP), which was shown to prevent endosymbiont escape from the bacteriocytes. However, following the insect systemic infection by pathogens, the bacteriome upregulates a cocktail of AMP encoding genes, including colA. The regulations that allow these contrasted immune responses remain unknown. In this short report, we provide evidence that an IMD-like pathway is conserved in two sibling species of cereal weevils, Sitophilus oryzae and Sitophilus zeamais. RNA interference (RNAi) experiments showed that imd and relish genes are essential for (i) colA expression in the bacteriome under standard conditions, (ii) AMP up-regulation in the bacteriome following a systemic immune challenge, and (iii) AMP systemic induction following an immune challenge. Histological analyses also showed that relish inhibition by RNAi resulted in endosymbiont escape from the bacteriome, strengthening the involvement of an IMD-like pathway in endosymbiont control. We conclude that Sitophilus' IMD-like pathway mediates both the bacteriome immune program involved in endosymbiont seclusion within the bacteriocytes and the systemic and local immune responses to exogenous challenges. This work provides a striking example of how a conserved immune pathway, initially described as essential in pathogen clearance, also functions in the control of mutualistic associations.
\end{abstract}

Keywords: Endosymbiosis, Bacteriocyte, Antimicrobial peptide, Sitophilus, Innate immunity, Compartmentalization

\section{Main text}

Host-symbiont associations are widespread in nature and exhibit a variety of interactions ranging from parasitism to mutualism. Insects living on nutritionally unbalanced diets are prone to establish long-term mutualistic relationships with vertically transmitted intracellular bacteria (endosymbionts) that complement their diet, improve their metabolism and reproduction, and impact many host adaptive traits, including immunity and defense against pathogens [1-7]. While the metabolic, ecological and evolutionary

\footnotetext{
* Correspondence: abdelaziz.heddi@insa-lyon.fr

'Univ Lyon, INSA-Lyon, INRA, BF2i, UMR0203, F-69621 Villeurbanne, France Full list of author information is available at the end of the article
}

features of these interactions have been well described [8-10], the mechanisms allowing the persistence of such associations remain largely unexplored. Beneficial bacteria are essential for the association's survival but represent a constant immune challenge for the host. Insect immunity must preserve endosymbionts and control their load and location while being able to cope with potential environmental infections by microbial intruders. This dilemma is more puzzling considering that both pathogenic and beneficial interactors display conserved immune elicitors, the microbe-associated molecular patterns (MAMPs; e.g., peptidoglycan (PGN)), that are sensed by innate immune receptors. In long-lasting 
endosymbiotic associations, host-symbiont coevolution is accompanied by a bacterial genomic erosion that generally results in the loss of bacterial genes that are redundant or harmful for the association [8, 9, 11]. Among these, genes encoding enzymes involved in MAMP synthesis can be lost, such as in Buchnera aphidicola, the pea aphid's primary endosymbiont [12]. This feature was suggested to enable endosymbionts to avoid recognition by the host's immune system. On the host's side, many insects have selected a compartmentalization strategy that consists in secluding endosymbionts within specialized host cells, the bacteriocytes (which form a bacteriome organ in some insect species), limiting thereby their direct contact with the host systemic immune response [5, 10, 13-16]. Compartmentalization plays several functions, including centralization of host-symbiont metabolic exchanges $[17,18]$, control of endosymbiont load and location [19-23], and endosymbiont preservation from exogenous pathogens [24]. Similar symbiont compartmentalizations can be found in amphibians [25], plants [26, 27], cnidarians [28], and mollusks [29, 30]. For instance, in the squid Euprymna scolopes, symbiont compartmentalization in a light organ is essential for efficient light production and symbiont population control [31-33].

Among insects, the cereal weevil Sitophilus spp. mutualistic association with the Gram-negative bacterium Sodalis pierantonius [13, 34, 35] is relevant to address endosymbiont-host immune interactions. S. pierantonius has been acquired recently by cereal weevils (less than 30,000 years ago) [36], likely following the replacement of Candidatus Nardonella, the ancestor endosymbiont of the Dryophthoridae family [37, 38]. The genome of $S$. pierantonius has not experienced the size shrinkage usually observed in endosymbionts, and it notably retains genes encoding enzymes involved in MAMP synthesis, including PGN [34]. Injection of S. pierantonius in the weevil's hemolymph elicits a systemic immune response, attested by a high induction of antimicrobial peptide (AMP)-encoding genes [39]. Under standard conditions (i.e., in the absence of infection with free-living bacteria), we have previously shown that the weevil's bacteriome displays a specific immune program, the so-called bacteriome "internal response" [40], which is essential for $S$. pierantonius seclusion. Despite the massive endosymbiont load, most AMP-encoding genes are weakly expressed in the bacteriome, with the notable exception of the coleoptericin $A(\operatorname{col} A)$ gene $[17,20,39,41,42]$. ColA peptide was shown to enter the bacterial cytosol and to interact with several bacterial proteins, including the chaperonin GroEL, resulting in the inhibition of bacterial cytokinesis and the formation of gigantic, filamentous, and polyploid endosymbionts [20, 43]. In vivo functional analyses revealed that ColA functions as a "molecular guard" that prevents endosymbiont escape from the bacteriome [20]. The bacteriome is also able to mount a local immune response upon systemic infection by free-living microbes, called the bacteriome "external response" [40]. Bacteriomes of challenged insects upregulate the expression of a cocktail of AMP-encoding genes, including colA but also coleoptericin $B(\operatorname{col} B)$ and sarcotoxin [24]. The molecular basis of these contrasted immune responses remains elusive, as well as more generally the immune pathways regulating the weevil immune response to Gram-negative bacterial infections.

Knowledge on insect humoral immunity is largely acquired from the Drosophila model, in which Gramnegative bacteria are detected by immune receptors that recognize their DAP-type PGN, or derived monomeric fragments, including the tracheal cytotoxin (TCT) $[44,45]$. PGN or TCT recognition triggers the activation of a signaling cascade, the immune deficiency (IMD) pathway, that leads to the activation and nuclear translocation of the NF$\mathrm{\kappa B}$ transcription factor Relish, which in turn upregulates AMP expression [46]. Since its discovery in Drosophila, the IMD pathway was described in many other species [47-50], attesting its high conservation across insect groups.

In this study, we first sought to determine whether the IMD pathway is conserved in the cereal weevil. We looked in two weevil sibling species, Sitophilus zeamais and Sitophilus oryzae, at both the gene conservation and the expression patterns of $i m d$ and relish, which are the two key genes of the IMD pathway in Drosophila. Both imd and relish gene transcripts had previously been found in the rice weevil S. oryzae transcriptome [24, 42], and partial sequences were subsequently identified in $S$. zeamais based on $S$. oryzae sequences. We next examined imd and relish expression patterns in the bacteriome and in the rest of the larva (larval body after bacteriome dissection, hereafter referred to as "the carcass"), under standard conditions and after an immune challenge. To avoid any potential interference of living bacteria that can actively modulate host immunity, we chose to inject larvae with purified Escherichia coli TCT. Injection with sterile phosphate buffer saline (PBS) is the control condition in this study and represents the basal expression of all genes studied. Systemic TCT injection in $S$. zeamais larvae efficiently induced the expression of three AMPs used as reporter genes for immune activation (colA, colB, and sarcotoxin), at $6 \mathrm{~h}$ post-injection, as compared to larvae injected with PBS (Additional file 1). This immune response is similar to what has been reported in Drosophila [44] and to what is observed when injecting various Gram-negative bacteria in the weevil's hemolymph [24, 39, 51]. In both weevil species, imd and relish genes were expressed in the bacteriome and the carcass (Fig. 1). Imd expression did not show any difference between PBS- and TCTinjected larvae in both the bacteriome and the carcass 
a imd expression in S. zeamais

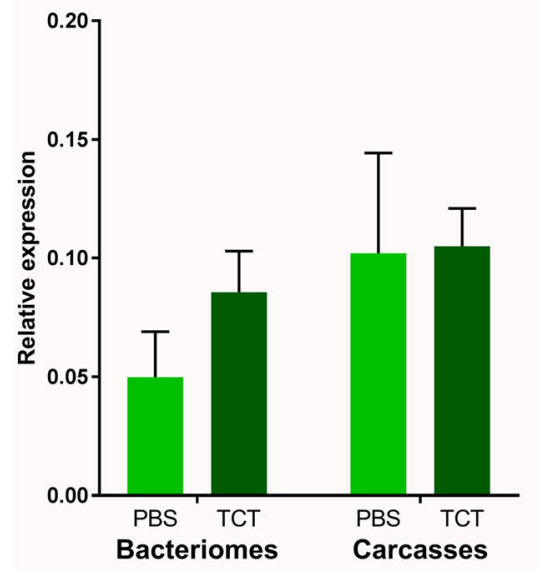

C relish expression in S. zeamais

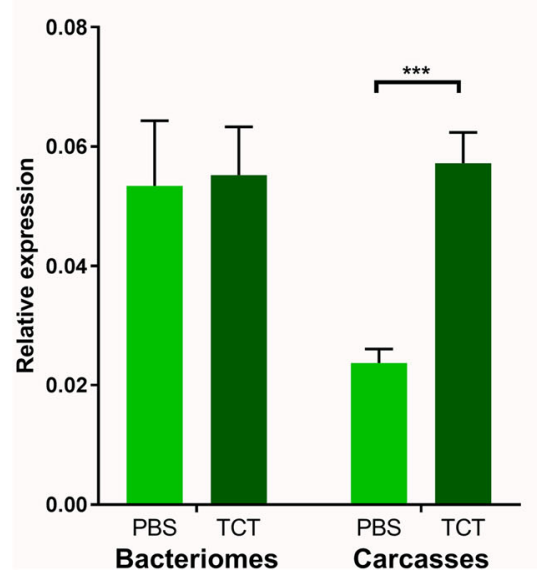

b imd expression in S. oryzae

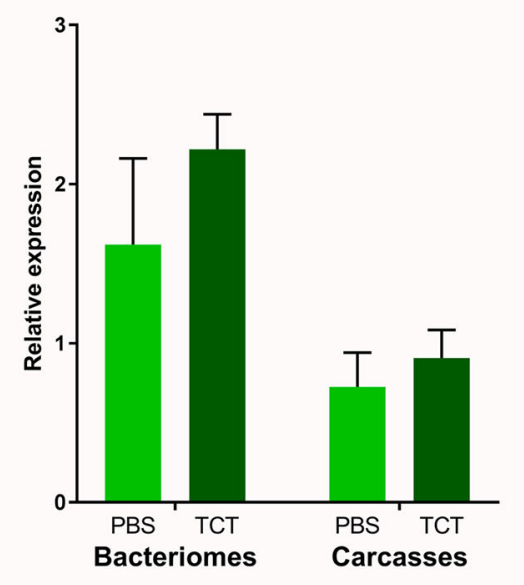

d relish expression in S. oryzae

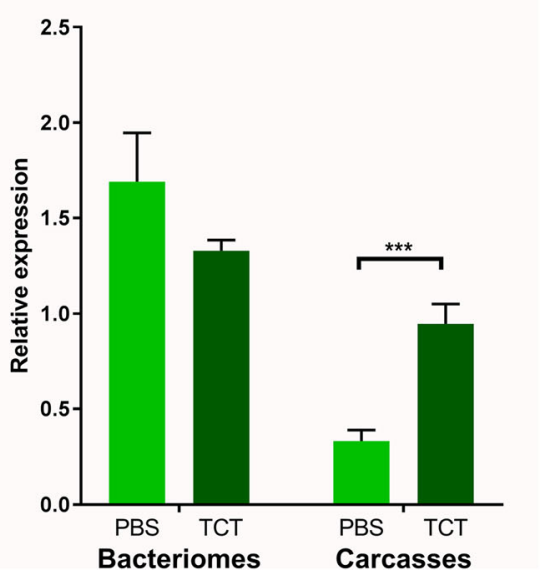

Fig. 1 imd and relish expression patterns. imd and relish expression was measured by RT-qPCR in bacteriomes and carcasses. Tissues were dissected $6 \mathrm{~h}$ following either PBS or TCT injection, 6 days after gfp dsRNA injection. Gene expression was normalized by the geometric mean of two housekeeping gene expressions, rpl29 and mdh. a imd expression in S. zeamais. b imd expression in S. oryzae. c relish expression in S. zeamais. d relish expression in S. oryzae. The mean and standard error for five independent replicates are represented. Asterisks indicate a significant difference between two conditions based on a Welch's $t$ test $\left({ }^{*} p<0.05 ;{ }^{* *} p<0.01 ;{ }^{* * *} p<0.001\right)$

(Fig. 1a, b). Following insect challenge with TCT, relish expression level remained stable in the bacteriome but it highly increased in the larval carcass (Fig. 1c, d). The existence of the genes and transcripts associated with these two components in the bacteriome and the carcass suggests that an IMD-like pathway is conserved in the cereal weevil, similarly to Drosophila [52], the coleopteran Tribolium castaneum [47], and the dipteran Glossina morsitans [48]. It is noteworthy that the IMD pathway has been lost in the pea aphid Acyrtosiphon pisum, along with many immune genes including peptidoglycan recognition proteins and known AMPs. This immune gene degeneration was speculated to be an adaptation of aphids to their symbiotic association $[53,54]$.

To assess whether and how this IMD-like pathway is involved in the weevil's immune responses, we first used
RNA interference (RNAi) against imd transcripts in both species [55]. The steady-state levels of imd transcripts drastically decreased following larval injection with dsRNA in both the bacteriome and the carcass and in all conditions (Additional file 2). As expected, TCT injection induced AMP expression in the carcass as compared to PBS-injected larvae (Fig. 2a, b). Importantly, imd RNAi led in both weevil species to a significant inhibition of the basal and induced AMP expression in the carcass, after PBS and TCT injection, respectively. IMD is thus required for systemic AMP induction following the injection of Gram-negative bacterial PGN in Sitophilus, similarly to what has been reported in other arthropods [52, 56, 57]. Interestingly, we showed that the steady-state levels of all AMP transcripts were strongly downregulated in the bacteriome, following imd 


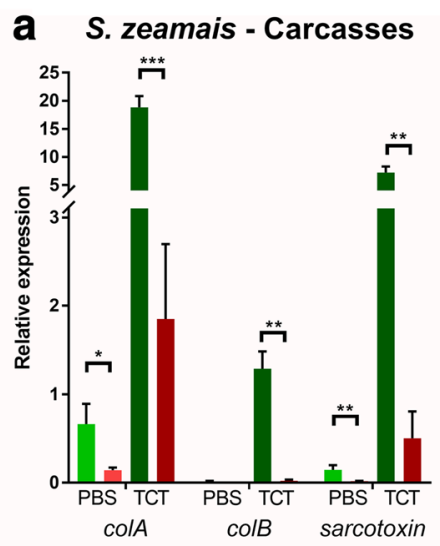

\section{b S. oryzae - Carcasses}
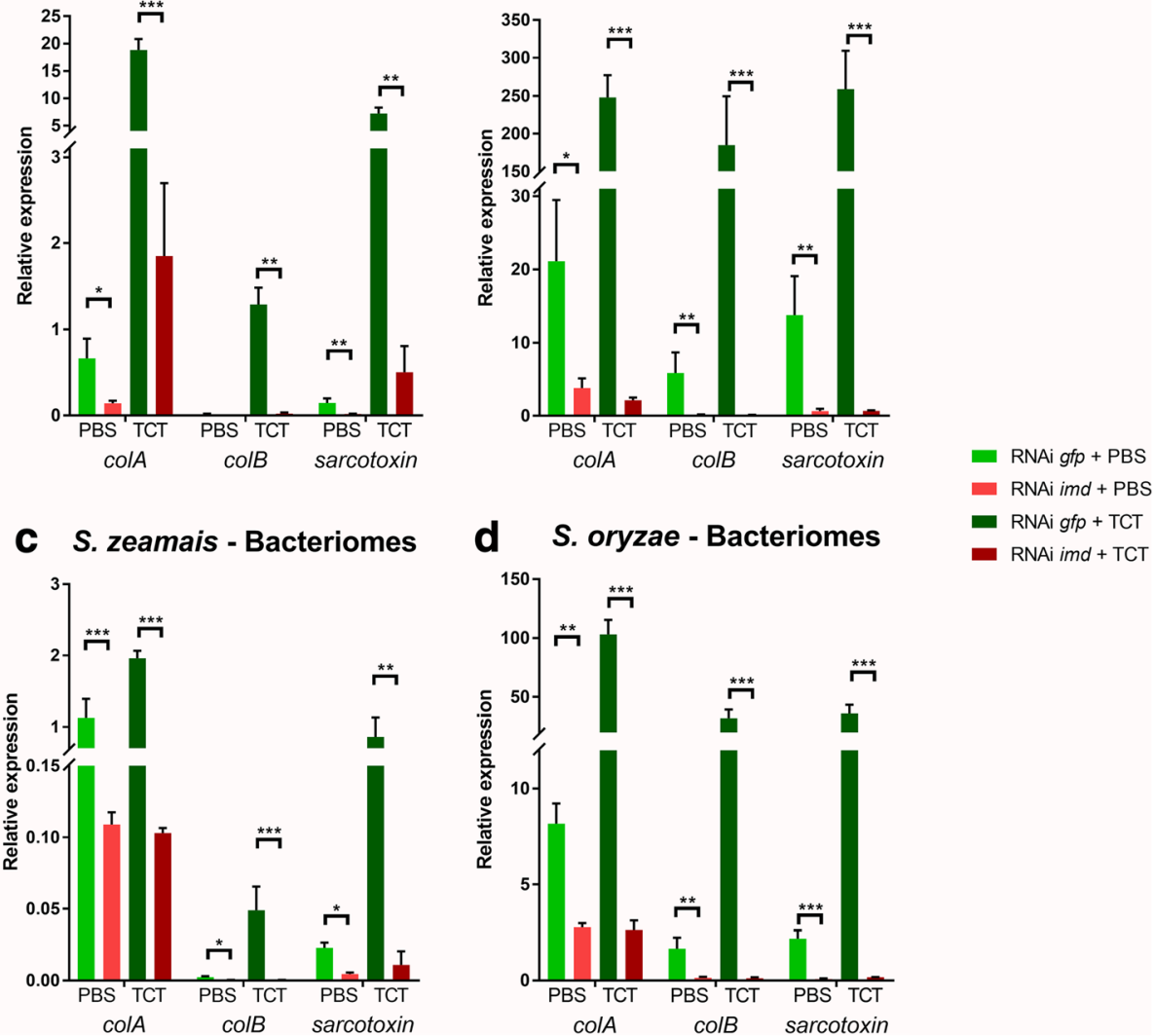

Fig. 2 AMP expression is IMD-dependent in S. zeamais and S. oryzae. colA, colB, and sarcotoxin expressions were measured by RT-qPCR 6 h after either PBS or TCT injections, following gfp or imd extinction. Gene expression was normalized by the geometric mean of two housekeeping gene expressions, rp/29 and mdh. a AMP expression in S. zeamais' carcasses. b AMP expression in S. oryzae's carcasses. c AMP expression in S. zeamais' dissected bacteriomes. d AMP expression in S. oryzae's dissected bacteriomes. The mean and standard error for five independent replicates are represented. Asterisks indicate a significant difference between two conditions based on a Welch's $t$ test $\left({ }^{*} p<0.05 ;{ }^{* *} p<0.01\right.$; $\left.{ }^{* * *} p<0.001\right)$

inhibition by RNAi in PBS-injected larvae of both $S$. zeamais and $S$. oryzae (Fig. 2c, d). These findings indicate that, in the absence of infection with exogenous bacteria, all three AMPs, whether strongly (colA) or weakly expressed (colB and sarcotoxin), are under tight regulation of IMD in the bacteriome. Similarly to larval challenge with the Gram-negative bacterium Dickeya dadantii [24], injection of larvae with TCT resulted in the upregulation of all three AMPs in the bacteriome, when compared to PBS-injected larvae. The induction of the bacteriome "external response" was strongly reduced in larvae treated with imd RNAi, in both species (Fig. 2c, d). Therefore, IMD not only activates the systemic immune response to TCT, but it also mediates the bacteriome "internal" and "external" responses. Despite different expression patterns, systemic and bacteriome local AMP expressions seem to be regulated by the same pathway. It was reported in Drosophila that AMP expression and regulation can be tissue-dependent. For instance, the drosomycin gene expression was shown to be Toll-dependent in the fat body [58],
IMD-dependent in the epithelia [59], while its constitutive expression in the salivary glands and the gut has been attributed to the homeobox gene caudal $[60,61]$. It will be interesting to figure out whether the regulation of AMP expression by IMD applies to all AMPs and all tissues in the weevil, or if other pathways are involved.

Because IMD appears to control two distinct responses in the weevil bacteriome, i.e. the "internal" symbiosisrelated program and the "external" immune response to TCT injection, we wondered whether this pathway could split into two distinct transduction signals downstream of IMD, leading to the differential recruitment of transcription factors that could account for the two responses. To test this hypothesis, we inhibited relish expression by RNAi (Additional file 2) and monitored AMP expression in PBS-injected and TCT-injected larvae. Remarkably, AMP transcript profiles were highly similar when compared with those following imd inhibition, in all conditions and in both weevil species (Fig. 3). These data indicate that Relish is required for the basal 


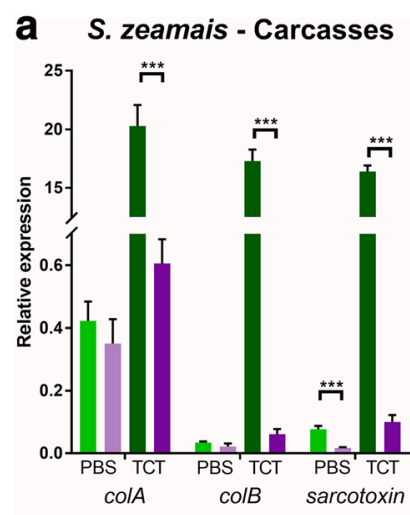

C S. zeamais - Bacteriomes

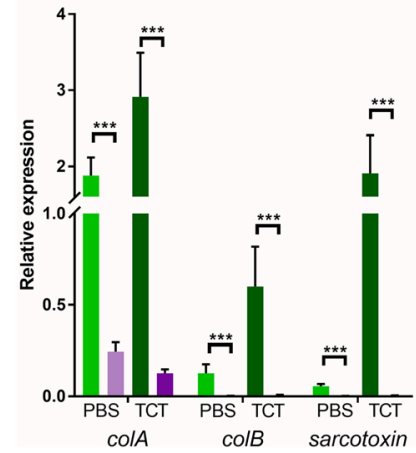

b S. oryzae - Carcasses

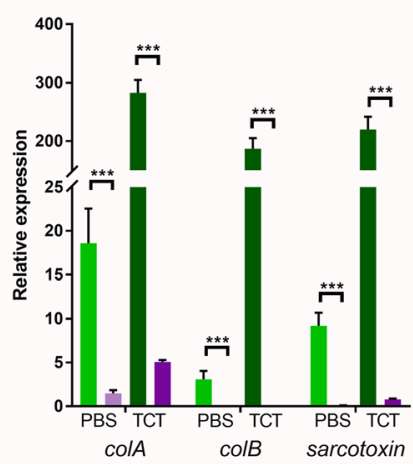

- RNAi gfp + PBS

- RNAi relish + PBS

- RNAi gfp + TCT

d S. oryzae-Bacteriomes

- RNAi relish + TCT

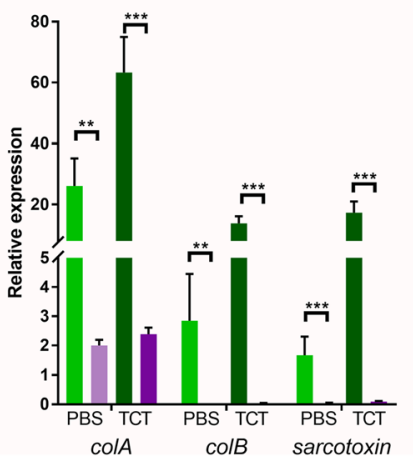

Fig. 3 AMP expression is Relish-dependent in S. zeamais and S. oryzae. colA, colB, and sarcotoxin expressions were measured by RT-qPCR 6 h after either PBS or TCT injections, following gfp or relish extinction. Gene expression was normalized by the geometric mean of two housekeeping gene expressions, rpl29 and mdh. a AMP expression in S. zeamais' carcasses. b AMP expression in S. oryzae's carcasses. c AMP expression in S. zeamais' dissected bacteriomes. d AMP expression in S. oryzae's dissected bacteriomes. The mean and standard error for five independent replicates are represented. Asterisks indicate a significant difference between two conditions based on a Welch's $t$ test $\left({ }^{*} p<0.05 ;{ }^{* *} p<0.01 ;{ }^{* *} p<0.001\right)$

expression of most AMPs in the carcass of PBS-injected larvae, as well as for the systemic AMP upregulation in response to TCT injection (Fig. 3a, b). Moreover, Relish was required for the bacteriome "internal" response program in PBS-injected larvae, as colA expression was significantly decreased in larvae subjected to relish RNAi (Fig. 3c, d). Finally, Relish was also required for AMP induction in the bacteriome after TCT injection (Fig. 3c, d). These data indicate that the bacteriome "internal" and "external" immune responses, as well as the systemic immune response, are all Relish-dependent in both $S$. zemais and S. oryzae. Nonetheless, additional transcription factors might be at play. A qualitatively or quantitatively different set of transcription factor binding sites upstream of the respective AMP encoding genes could result in their differential expression. For instance, Drosophila's Pickle specifically inhibits Relish homodimers, therefore only impacting the expression of AMP genes containing two Relish binding sites [62]. Sitophilus genome will be soon available, which will open a field of investigation on the AMP-encoding gene promoting sequences and the corresponding transcription factors.
Finally, FISH experiments were conducted on $S$. zeamais larvae after relish inhibition, in order to specifically localize $S$. pierantonius and to detect any potential loss of endosymbiont control. Symbionts were seen "leaking" from the bacteriome 6 days after relish dsRNA injection (Fig. 4b), and many bacteria were seen in the larval fat body 10 days after relish dsRNA injection (Fig. 4c). This phenotype is similar to what was previously observed following colA inhibition [20] and confirms that, by regulating colA expression, this IMD-like pathway is directly involved in symbiosis compartmentalization.

Taken together, these findings indicate that colA expression in the bacteriome is under the control of an IMD-like pathway, involving at least IMD and Relish. Even though several components of the IMD pathway have been suggested to be involved in symbiotic interactions [63-65], this is the first demonstration that an IMD-like pathway is involved in endosymbiont control. Nevertheless, because colA expression in the bacteriome was not completely inhibited under either imd or relish RNAi conditions, we cannot rule out the implication of another pathway in colA regulation, although this 

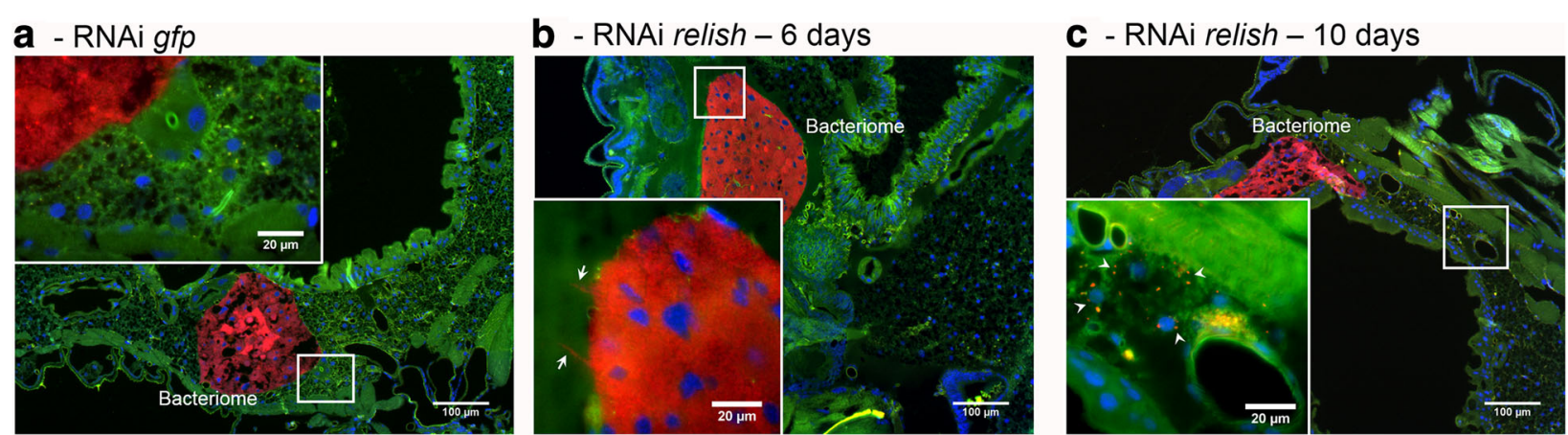

Fig. 4 S. pierantonius localization by FISH following relish inhibition in S. zeamais larvae. Red, S. pierantonius; green, autofluorescence; blue, DAPI. a Six days following gfp dsRNA injection. b Six days following relish dsRNA injection. Arrows point at endosymbionts exiting from the bacteriome. $\mathbf{c}$ Ten days following relish dsRNA injection. Arrowheads point at endosymbionts present in the fat body

incomplete downregulation could also be the result of the incomplete RNAi-driven knock-down of imd and relish expression. Strikingly, the "internal response" and the "external response" are both under the same IMD/ Relish-dependent regulation. What remains intriguing is that $\operatorname{col} A$, despite its strong expression in the bacteriome under basal conditions, is under the same regulation as other AMPs, whose genes are weakly expressed under basal conditions. The IMD dependency of colA expression under basal conditions argues in favor of a symbiont-induced basal expression rather than a symbiont-independent expression. This hypothesis is reinforced by previous results showing that colA expression matches the drastic symbiont density changes along the insect lifecycle $[40,66]$. Sensing the endosymbiont load would allow the host to modulate the internal response accordingly. As endosymbionts are exclusively intracellular, they could be sensed by an intracellular receptor, similar to the Drosophila PGRP-LE [67], whereas exogenous pathogens could be recognized by an extracellular or transmembrane receptor, similar to the Drosophila PGRP-LC [68, 69]. Such a dichotomous mechanism would allow distinguishing endosymbionts and pathogens at the recognition step and could differentially impact AMP expression while activating the same IMD pathway.

The data presented here strongly suggest that the specific and fine-tuned regulation of the bacteriome immune responses involves more complex mechanisms beyond a simple dichotomy in the implicated signal transduction pathways. Deciphering such complex regulations is likely to require the study of potential epigenetic markers, such as chromatin and histone modifications, that are increasingly shown to be involved in symbiotic interactions [70]. This will include addressing the possibility of non-coding RNA implication in the host immune regulations and their potential manipulation by the endosymbiont. Recent studies in insects have shown that several microRNAs specifically target and regulate immune genes, including AMPs [71, 72], and can mediate host-symbiont interactions as shown in the Aedes aegypti-Wolbachia association [73].

\section{Conclusion}

We demonstrated that (i) the weevil's immune system expresses a functional IMD-like pathway; (ii) this IMDlike pathway regulates the systemic immune response to Gram-negative bacterial MAMPs; and (iii) both the "external" and "internal" bacteriome immune responses are IMD/Relish-dependent. Interestingly, this study uncovers that a highly conserved immune pathway is involved in both the weevil immune response to microbe intruders and in the regulation of the symbiosis-related specific program. This is the first report showing that an insect endosymbiosis compartmentalization strategy relies on an IMD-like immune pathway. The finding that IMD and Relish regulate both the internal and external responses of the weevil bacteriome is the first milestone on the long path to the full understanding of immune adaptations to endosymbiosis.

\section{Methods}

Biological material and sample preparation

Sitophilus weevils were reared on wheat grains at $27.5^{\circ} \mathrm{C}$ and at $70 \%$ relative humidity [74]. The Lagoa (S. zeamais) and Bouriz (S. oryzae) strains were chosen in this work because they are devoid of any facultative symbionts, including Wolbachia.

Insect bacteriomes and carcasses were dissected in buffer A $(25 \mathrm{nM} \mathrm{KCl}, 10 \mathrm{nM} \mathrm{MgCl} 2,250 \mathrm{nM}$ Sucrose, $35 \mathrm{nM}$ Tris/ $\mathrm{HCl}, \mathrm{pH}=7.5$ ). For RNA extraction, at least five organs or whole organisms per condition were pooled and stored at $-80{ }^{\circ} \mathrm{C}$, and each sampling was independently repeated five times. 


\section{Identification of genes of interest}

The AMP-encoding genes $\operatorname{col} A, \operatorname{col} B$, and sarcotoxin were identified in $S$. zeamais and S. oryzae from previous studies [39, 42], as well as imd and relish in $S$. oryzae [24, 42]. Imd and relish in S. zeamais were identified based on the homology with $S$. oryzae sequences and unpublished genomic and transcriptomic data. The respective sequences can be found under the following accession numbers: MF952871 and MF952872.

\section{TCT injections}

Injections were made on fourth instar larvae challenged with a $0.2 \mathrm{mM}$ TCT solution purified from $E$. coli as previously described [44]. Fifty-five nanoliters was injected into the hemolymph using a Nanoject II (Drummond). Sterile PBS was used as a negative control. Larvae were then incubated in wheat flour at $27.5{ }^{\circ} \mathrm{C}$ and at $70 \%$ relative humidity during $6 \mathrm{~h}$.

\section{dsRNA synthesis and injection}

dsRNA was prepared as described previously [55]. Primers used for T7 DNA fragments are listed in Additional file 3 and were designed to amplify a fragment from 200 to $250 \mathrm{pb}$. Fragments were amplified with a Taq'ozyme kit (Ozyme) and purified with a GenElute PCR Clean-up kit (Sigma-Aldrich), following the manufacturer's instructions. These fragments were used as templates for in vitro dsRNA synthesis, using a MEGAscript RNAi Kit (Ambion). After synthesis, the dsRNA was precipitated overnight at $-80{ }^{\circ} \mathrm{C}$ with $0.3 \mathrm{M}$ sodium acetate, $1.5 \mu \mathrm{g}$ glycogen, and two volumes of $100 \% \mathrm{EtOH}$ and resuspended in water to a final concentration of $2.7 \mu \mathrm{g} / \mu \mathrm{l}$. The purity and the integrity were determined with a Nanodrop ${ }^{\oplus}$ spectrophotometer (Thermo Scientific) and by agarose gel electrophoresis. The dsRNA was kept at $-20{ }^{\circ} \mathrm{C}$ prior to injection within the following 7 days. Fifty nanograms of dsRNA was injected into the hemolymph of third instar larvae with a Nanoject II (Drummond). They were then kept on wheat flour for 6 to 10 days, at $27.5{ }^{\circ} \mathrm{C}$ and at $70 \%$ relative humidity.

\section{Total RNA extraction and reverse transcription}

Total RNA from whole larvae and carcasses was extracted with TRIzol reagent (Invitrogen) following the manufacturer's instructions. RNA was incubated with $1 \mathrm{U} / \mu \mathrm{g}$ of RQ1 RNase-free DNase (Promega) for $30 \mathrm{~min}$ at $37{ }^{\circ} \mathrm{C}$ and purified using Nucleospin RNAClean-up (Macherey-Nagel). Total RNA from bacteriomes was extracted and purified using RNAqueous Micro (Ambion), which allows for a better RNA yield from small tissue samples. After purification, the RNA concentration was measured with a Nanodrop ${ }^{\circ}$ spectrophotometer (Thermo Scientific), and RNA quality was checked using agarose gel electrophoresis. Reverse transcription into the first strand cDNA was carried out using the iScript ${ }^{\mathrm{tm}}$ cDNA Synthesis Kit (Bio-Rad).

\section{Real-time RT-qPCR transcript quantification}

The transcript quantification was performed with a CFX Connect Real-Time detection system (Bio-Rad) using the LightCycler Fast Start DNA Master SYBR Green I kit (Roche Diagnostics). Data were calculated using the ratio of the target cDNA concentration to the geometric mean of two normalizing gene concentrations: ribosomal protein L29 (rpL29) and malate dehydrogenase ( $m d h$ ). Primers were designed to amplify fragments of approximately 150-200 bp. A complete list of the primers can be found in Additional file 3.

The PCR reactions were carried out in Hard-Sell 96well PCR plates (Bio-Rad) in a final volume of $10 \mu \mathrm{l}$, containing $2.5 \mu \mathrm{l}$ of cDNA samples (diluted fivefold) with $0.5 \mu \mathrm{l}$ of $10 \mathrm{mM}$ of each primer, $1.5 \mu \mathrm{l} \mathrm{H}_{2} \mathrm{O}$, and $5 \mu \mathrm{l}$ of Sybr Mastermix. After $5 \mathrm{~min}$ at $95^{\circ} \mathrm{C}$, the cycling conditions were as follows: 45 cycles at $95^{\circ} \mathrm{C}$ for $10 \mathrm{~s}, 56^{\circ} \mathrm{C}$ for $20 \mathrm{~s}$, and $72{ }^{\circ} \mathrm{C}$ for $30 \mathrm{~s}$. For product identification, a melting curve was constructed at the end of each PCR by heating for $30 \mathrm{~s}$ at $66^{\circ} \mathrm{C}$ and then increasing the temperature up to $95{ }^{\circ} \mathrm{C}$ with increment rates of $0.11{ }^{\circ} \mathrm{C} / \mathrm{s}$. Reactions were terminated by cooling at $40{ }^{\circ} \mathrm{C}$ for $30 \mathrm{~s}$. For each individual sample, the crossing point and the concentration of the gene transcripts were determined.

\section{Statistical analyses}

Transcriptomic data were analyzed by pairwise comparisons using a Welch $t$ test on the log-transformed gene expression data. The effect of a factor was considered to be significant with a $p$ value $<0.05$. All analyses and graphical figures were made using $\mathrm{R}$ software v3.1.1 [75], as well as GraphPad Prism v7 for Windows, GraphPad Software, La Jolla California USA, www.graphpad.com. Graphical figures represent the mean of all replicates for each point. Error bars represent the standard error calculated as $\sigma / \sqrt{ } n$, where $\sigma$ is the standard deviation and $n$ is the number of replicates.

\section{Immunohistochemistry \\ Sample preparation for histology}

Samples were fixed in PFA $4 \%$. After 1 week at $4{ }^{\circ} \mathrm{C}$, the fixative was replaced by several washings with $\mathrm{PBS}$ before embedding the tissue in $1.3 \%$ agar. Subsequently, the samples were dehydrated through a graded ethanol (EtOH) series and transferred to butanol-1, at $4{ }^{\circ} \mathrm{C}$, overnight. Samples in agar were then embedded in melted Paraplast. Tissue sections ( $3-\mu \mathrm{m}$ thick) were cut using an LKB Historange microtome. Sections were placed on poly-lysine-coated slides, dried overnight in a $37{ }^{\circ} \mathrm{C}$ oven, and stored at $4{ }^{\circ} \mathrm{C}$ prior to further treatments. 


\section{S. pierantonius localization by fluorescence in situ hybridization} After methylcyclohexane dewaxing, sections were covered with a drop of $70 \%$ acetic acid. Deproteinization of slides was performed in hydrochloric acid $0.01 \mathrm{~N}$ with pepsin $0.1 \mathrm{mg} / \mathrm{ml}$ for $10 \mathrm{~min}$ at $37^{\circ} \mathrm{C}$. The sections were then prehybridized, hybridized with a $S$. pierantoniusspecific 5 '-end TAMRA-labeled oligo-probe targeting 16S RNA (TAMRA-ACC-CCC-CTC-TAC-GAG-AC-3', $10 \mu \mathrm{g} / \mathrm{mL}$ ), washed, and then mounted in PermaFluor Mounting Fluid (ThermoScientific) containing $3 \mu \mathrm{g} / \mathrm{ml}$ of 4',6-diamidino-2-phenylindole (DAPI), as previously described [15].

Images were acquired with an epifluorescence microscope (Olympus IX81 equipped with a HQ535/50 filter for green signal, D470/40 for blue signal, and HQ610/75 for red signal) and captured using an F-ViewII camera and the cellSens software (Olympus). Images were treated and analyzed using Image (release 1.47v).

\section{Additional files}

Additional file 1: AMP expression following TCT injection in S. zeamais. colA, colB, and sarcotoxin expressions were measured by RT-qPCR in whole larvae $6 \mathrm{~h}$ following either PBS or TCT injection, 6 days after gfp dsRNA injection. Gene expression was normalized by the geometric mean of two housekeeping gene expressions, rp/29 and mdh. The mean and standard error for five independent replicates are represented. Asterisks indicate a significant difference between two conditions based on a Welch's $t$ test $\left({ }^{*} p<0.05 ;{ }^{* *} p<0.01 ;{ }^{* * *} p<0.001\right)$. (TIFF $441 \mathrm{~kb}$ )

Additional file 2: imd and relish inhibition by RNAi in S. zeamais (a) and S. oryzae (b). imd and relish expressions were measured by RT-qPCR in bacteriomes and carcasses. Tissues were dissected $6 \mathrm{~h}$ following either PBS or TCT injection, 6 days after gfp, imd, or relish dsRNA injection. Gene expression was normalized by the geometric mean of two housekeeping gene expressions, rp/29 and $m d h$. Raw data (mean \pm SD) as well as inhibition percentages are provided. Percentages were calculated as follows: $\%=\left(1-\frac{i m d \text { RNAi or relish RNAi }}{\text { off RNA }}\right) \times 100$; using the mean of five independent measurements for each value. Asterisks indicate a significant difference between a condition and its corresponding gfp RNAi control based on a Welch's $t$ test $\left({ }^{*} p<0.05 ;{ }^{* *} p<0.01 ;{ }^{* * *} p<0.001\right)$. (XLSX $11 \mathrm{~kb}$ )

Additional file 3: List of primers used for dsRNA synthesis and RTqPCR. (XLSX $12 \mathrm{~kb}$ )

\section{Abbreviations}

AMP: Antimicrobial peptide; Col: Coleoptericin; DAP: Diaminopimelic acid; FISH: Fluorescent in situ Hybridization; IMD: Immune deficiency; MAMP: Microbial-associated molecular pattern; PBS: Phosphate buffer saline; PGN: Peptidoglycan; RNAi: RNA interference; TCT: Tracheal cytotoxin

\section{Acknowledgments}

The authors sincerely thank Séverine Balmand, Catherine Fiol, Sergio López-Madrigal, Julien Orlans, Nicolas Parisot, and Agnès Vallier for their valuable help on animal rearing and sampling. We also thank Dominique Mengin-Lecreulx and Mireille Hervé (Université Paris-Sud, Orsay, France) for generously providing highly purified TCT used for larvae injections. QPCR was performed at Développement de Techniques et Analyse Moléculaire de la Biodiversité (DTAMB), from the Bio Environnement et Santé (BioEnviS) Research Federation.

\section{Funding}

This work was supported by INRA, INSA-Lyon, and the French ANR-13-BSV70016-01 (IMetSym). JM was also funded by a doctoral grant from the French Ministry of Higher Education and Research.

\section{Availability of data and materials}

All data generated or analyzed in this study are included in this published article and its supplementary information files.

\section{Authors' contributions}

JM performed the RNAi experiments, RT-qPCR assays, and the FISH experiments and performed the statistical analysis and drafted the manuscript. CVM and FM identified the genes of interest and participated in the design of the experiments. AZR and AH conceived the study, participated in its design and coordination, and participated in the manuscript drafting. All authors read and approved the final manuscript.

\section{Competing interests}

The authors declare that they have no competing interest.

\section{Publisher's Note}

Springer Nature remains neutral with regard to jurisdictional claims in published maps and institutional affiliations.

\section{Author details}

'Univ Lyon, INSA-Lyon, INRA, BF2i, UMR0203, F-69621 Villeurbanne, France. ${ }^{2}$ Present address: Global Health Institute, School of Life Sciences, Ecole Polytechnique Fédérale de Lausanne (EPFL), Station 19, 1015 Lausanne, Switzerland.

Received: 13 November 2017 Accepted: 28 December 2017 Published online: 08 January 2018

\section{References}

1. Wicker C. Differential vitamin and choline requirements of symbiotic and aposymbiotic S. oryzae (Coleoptera: Curculionidae). Comp Biochem Physiol Part A Physiol. 1983;76(1):177-82.

2. Heddi A, Lefebvre F, Nardon P. Effect of endocytobiotic bacteria on mitochondrial enzymatic-activities in the weevil Sitophilus-Oryzae (Coleoptera, Curculionidae). Insect Biochem Mol Biol. 1993;23(3):403-11.

3. Douglas AE. Nutritional interactions in insect-microbial symbioses: aphids and their symbiotic bacteria Buchnera. Annu Rev Entomol. 1998:43(1):17-37.

4. Pais R, Lohs C, Wu Y, Wang J, Aksoy S. The obligate mutualist Wigglesworthia glossinidia influences reproduction, digestion, and immunity processes of its host, the tsetse fly. Appl Environ Microbiol. 2008;74:5965-74.

5. Sabree ZL, Kambhampati S, Moran NA. Nitrogen recycling and nutritional provisioning by Blattabacterium, the cockroach endosymbiont. Proc Natl Acad Sci U S A. 2009;106(46):19521-6.

6. Weiss BL, Wang J, Aksoy S. Tsetse immune system maturation requires the presence of obligate symbionts in larvae. PLoS Biol. 2011;9(5):e1000619.

7. Michalkova V, Benoit JB, Weiss BL, Attardo GM, Aksoy S. Vitamin B6 generated by obligate symbionts is critical for maintaining proline homeostasis and fecundity in tsetse flies. Appl Environ Microbiol. 2014;80(18):5844-53.

8. Bennett GM, Moran NA. Small, smaller, smallest: the origins and evolution of ancient dual symbioses in a phloem-feeding insect. Genome Biol Evol. 2013; 5(9):1675-88.

9. Latorre A, Manzano-Marín A. Dissecting genome reduction and trait loss in insect endosymbionts. Ann N Y Acad Sci. 2017;1389(1):52-75.

10. Baumann P. Biology of bacteriocyte-associated endosymbionts of plant sapsucking insects. Annu Rev Microbiol. 2005;59(1):155-89.

11. Moran NA, Bennett GM. The tiniest tiny genomes. Annu Rev Microbiol. 2014;68:195-215.

12. Shigenobu S, Watanabe H, Hattori M, Sakaki Y, Ishikawa H. Genome sequence of the endocellular bacterial symbiont of aphids Buchnera sp. APS Nature. 2000;407(6800):81-6.

13. Heddi A, Grenier AM, Khatchadourian C, Charles H, Nardon P. Four intracellular genomes direct weevil biology: nuclear, mitochondrial, principal endosymbiont, and Wolbachia. Proc Natl Acad Sci USA. 1999;96(12):6814-9.

14. von Dohlen CD, Kohler S, Alsop ST, McManus WR. Mealybug beta-proteobacterial endosymbionts contain gamma-proteobacterial symbionts. Nature. 2001; 412(6845):433-6.

15. Balmand S, Lohs C, Aksoy S, Heddi A. Tissue distribution and transmission routes for the tsetse fly endosymbionts. J Invertebr Pathol. 2013;112(Suppl):S116-22.

16. Stoll S, Feldhaar H, Fraunholz MJ, Gross R. Bacteriocyte dynamics during development of a holometabolous insect, the carpenter ant Camponotus floridanus. BMC Microbiol. 2010;10(1):308. 
17. Heddi A, Vallier A, Anselme C, Xin H, Rahbe Y, Wäckers F. Molecular and cellular profiles of insect bacteriocytes: mutualism and harm at the initial evolutionary step of symbiogenesis. Cell Microbiol. 2005;7(2):293-305.

18. Nakabachi A, Shigenobu S, Sakazume N, Shiraki T, Hayashizaki Y, Carninci P, et al. Transcriptome analysis of the aphid bacteriocyte, the symbiotic host cell that harbors an endocellular mutualistic bacterium, Buchnera. Proc Natl Acad Sci USA. 2005;102(15):5477-82.

19. Vigneron A, Masson F, Vallier A, Balmand S, Rey M, Vincent-Monégat C, et al. Insects recycle endosymbionts when the benefit is over. Curr Biol. 2014; 24(19):2267-73.

20. Login FH, Balmand S, Vallier A, Vincent-Monégat C, Vigneron A, Weiss-Gayet $M$, et al. Antimicrobial peptides keep insect endosymbionts under control. Science. 2011;334(6054):362-5.

21. Kono M, Koga R, Shimada M, Fukatsu T. Infection dynamics of coexisting beta- and gammaproteobacteria in the nested endosymbiotic system of mealybugs. Appl Environ Microbiol. 2008;74(13):4175-84.

22. Rio RVM, Wu Y-N, Filardo G, Aksoy S. Dynamics of multiple symbiont density regulation during host development: tsetse fly and its microbial flora. Proc Biol Sci. 2006;273(1588):805-14.

23. Simonet P, Duport G, Gaget $K$, Weiss-Gayet M, Colella S, Febvay G, et al. Direct flow cytometry measurements reveal a fine-tuning of symbiotic cell dynamics according to the host developmental needs in aphid symbiosis. Sci Rep. 2016;6:19967.

24. Masson F, Vallier A, Vigneron A, Balmand S, Vincent-Monégat C, ZaidmanRémy $A$, et al. Systemic infection generates a local-like immune response of the bacteriome organ in insect symbiosis. J Innate Immun. 2015;7(3):290-301.

25. Kerney R, Kim E, Hangarter RP, Heiss AA, Bishop CD, Hall BK. Intracellular invasion of green algae in a salamander host. Proc Natl Acad Sci USA. 2011;108(16):6497-502

26. Haag AF, Arnold MFF, Myka KK, Kerscher B, Dall'Angelo S, Zanda M, et al. Molecular insights into bacteroid development during Rhizobium-legume symbiosis. FEMS Microbiol Rev. 2013;37(3):364-83.

27. Pawlowski K, Demchenko KN. The diversity of actinorhizal symbiosis. Protoplasma. 2012;249(4):967-79.

28. Davy SK, Allemand D, Weis VM. Cell biology of cnidarian-dinoflagellate symbiosis. Microbiol Mol Biol Rev. 2012;76(2):229-61.

29. Distel DL, Lee HK, Cavanaugh CM. Intracellular coexistence of methano- and thioautotrophic bacteria in a hydrothermal vent mussel. Proc Natl Acad Sci USA. 1995;92(21):9598-602

30. McFall-Ngai M. Divining the essence of symbiosis: insights from the squidvibrio model. PLoS Biol. 2014;12(2):1-6.

31. Wier AM, Nyholm SV, Mandel MJ, Massengo-Tiassé RP, Schaefer AL, Koroleva I, et al. Transcriptional patterns in both host and bacterium underlie a daily rhythm of anatomical and metabolic change in a beneficial symbiosis. Proc Natl Acad Sci USA. 2010;107(5):2259-64.

32. Heath-Heckman E, Peyer S, Whistler C, Apicella M, Goldman W, McFall-Ngai M. Bacterial bioluminescence regulates expression of a host cryptochrome gene in the squid-vibrio symbiosis. MBio. 2013;4(2):1-10.

33. Schwartzman JA, Koch E, EAC H-H, Zhou L, Kremer N, MJ MF-N, et al. The chemistry of negotiation: rhythmic, glycan-driven acidification in a symbiotic conversatio. Proc Natl Acad Sci. 2015;112(2):566-71.

34. Oakeson KF, Gil R, Clayton AL, Dunn DM, von Niederhausern AC, Hamil C, et al. Genome degeneration and adaptation in a nascent stage of symbiosis. Genome Biol Evol. 2014;6(1):76-93.

35. Heddi A, Charles H, Khatchadourian C, Bonnot G, Nardon P. Molecular characterization of the principal symbiotic bacteria of the weevil Sitophilus oryzae: a peculiar G + C content of an endocytobiotic DNA. J Mol Evol. 1998;47(1):52-61.

36. Clayton AL, Oakeson KF, Gutin M, Pontes A, Dunn DM, von Niederhausern $A C$, et al. A novel human-infection-derived bacterium provides insights into the evolutionary origins of mutualistic insect-bacterial symbioses. PLoS Genet. 2012;8(11):e1002990.

37. Lefèvre C, Charles H, Vallier A, Delobel B, Farrell B, Heddi A. Endosymbiont phylogenesis in the dryophthoridae weevils: evidence for bacterial replacement. Mol Biol Evol. 2004;21(6):965-73.

38. Conord C, Despres L, Vallier A, Balmand S, Miquel C, Zundel S, et al. Longterm evolutionary stability of bacterial endosymbiosis in curculionoidea: additional evidence of symbiont replacement in the dryophthoridae family. Mol Biol Evol. 2008;25(5):859-68.

39. Anselme C, Pérez-Brocal V, Vallier A, Vincent-Monegat C, Charif D, Latorre A, et al. Identification of the weevil immune genes and their expression in the bacteriome tissue. BMC Biol. 2008;6:43.
40. Masson F, Zaidman-Rémy A, Heddi A. Antimicrobial peptides and cell processes tracking endosymbiont dynamics. Philos Trans R Soc Lond Ser B Biol Sci. 2016;371(1695):403-11.

41. Anselme C, Vallier A, Balmand S, Fauvarque M-O, Heddi A. Host PGRP gene expression and bacterial release in endosymbiosis of the weevil Sitophilus zeamais. Appl Environ Microbiol. 2006;72(10):6766-72.

42. Vigneron A, Charif D, Vincent-Monégat C, Vallier A, Gavory F, Wincker P, et al. Host gene response to endosymbiont and pathogen in the cereal weevil Sitophilus oryzae. BMC Microbiol. 2012;12(Suppl 1):S14.

43. Login $\mathrm{FH}$, Heddi A. Insect immune system maintains long-term resident bacteria through a local response. J Insect Physiol. 2013;59(2):232-9.

44. Stenbak CR, Ryu J-H, Leulier F, Pili-Floury S, Parquet C, Hervé M, et al. Peptidoglycan molecular requirements allowing detection by the Drosophila immune deficiency pathway. J Immunol. 2004;173:7339-48.

45. Leulier F, Parquet C, Pili-Floury S, Ryu J-H, Caroff M, Lee W-J, et al. The Drosophila immune system detects bacteria through specific peptidoglycan recognition. Nat Immunol. 2003:4:478-84.

46. Lemaitre B, Hoffmann J. The host defense of Drosophila melanogaster. Annu Rev Immunol. 2007;25(1):697-743.

47. Zou Z, Evans JD, Lu Z, Zhao P, Williams M, Sumathipala N, et al. Comparative genomic analysis of the Tribolium immune system. Genome Biol. 2007;8(8):R177.

48. Attardo GM, Abila PP, Auma JE, Baumann AA, Benoit JB, Brelsfoard CL, et al. Genome sequence of the tsetse fly (Glossina morsitans): vector of African Trypanosomiasis. Science. 2014;344(6182):380-6.

49. Cao X, He Y, Hu Y, Wang Y, Chen Y-R, Bryant B, et al. The immune signaling pathways of Manduca sexta. Insect Biochem Mol Biol. 2015;62:64-74.

50. Waterhouse RM, Kriventseva EV, Meister S, Xi Z, Alvarez KS, Bartholomay LC, et al. Evolutionary dynamics of immune-related genes and pathways in disease-vector mosquitoes. Science. 2007:316(5832):1738-43.

51. López-Madrigal S, Maire J, Balmand S, Zaidman-Rémy A, Heddi A. Effects of symbiotic status on cellular immunity dynamics in Sitophilus oryzae. Dev Comp Immunol. 2017;77:259-69.

52. Lemaitre B, Kromer-Metzger E, Michaut L, Nicolas E, Meister M, Georgel P, et al. A recessive mutation, immune deficiency (imd), defines two distinct control pathways in the Drosophila host defense. Proc Natl Acad Sci USA. 1995;92(21):9465-9.

53. International Aphid Genomics Consortium TIAG. Genome sequence of the pea aphid Acyrthosiphon pisum. PLoS Biol. 2010;8(2):e1000313.

54. Gerardo NM, Altincicek B, Anselme C, Atamian H, Barribeau SM, de Vos M, et al. Immunity and other defenses in pea aphids. Genome Biol. 2010;11(2):R21.

55. Vallier A, Vincent-Monégat C, Laurençon A, Heddi A. RNAi in the cereal weevil Sitophilus spp: systemic gene knockdown in the bacteriome tissue. BMC Biotechnol. 2009:9:44.

56. Hou F, He S, Liu Y, Zhu X, Sun C, Liu X. RNAi knock-down of shrimp Litopenaeus vannamei Toll gene and immune deficiency gene reveals their difference in regulating antimicrobial peptides transcription. Dev Comp Immunol. 2014;44(2):255-60.

57. Yokoi K, Koyama H, Minakuchi C, Tanaka T, Miura K. Antimicrobial peptide gene induction, involvement of Toll and IMD pathways and defense against bacteria in the red flour beetle. Results Immunol. 2012;2:72-82.

58. Lemaitre B, Nicolas E, Michaut L, Reichhart JM, Hoffmann JA, Hoffmann J, et al. The dorsoventral regulatory gene cassette spätzle/Toll/cactus controls the potent antifungal response in Drosophila adults. Cell. 1996;86(6):973-83.

59. Tzou P, Ohresser S, Ferrandon D, Capovilla M, Reichhart JM, Lemaitre B, et al. Tissue-specific inducible expression of antimicrobial peptide genes in Drosophila surface epithelia. Immunity. 2000;13(5):737-48.

60. Ryu J-H, Nam K-B, Oh C-T, Nam H-J, Kim S-H, Yoon J-H, et al. The homeobox gene caudal regulates constitutive local expression of antimicrobial peptide genes in Drosophila epithelia. Mol Cell Biol. 2004;24:172-85.

61. Ryu J-H, Kim S-H, Lee H-Y, Bai JY, Nam Y-D, Bae J-W, et al. Innate immune homeostasis by the homeobox gene caudal and commensal-gut mutualism in Drosophila. Science. 2008;319(5864):777-82.

62. Morris O, Liu X, Domingues C, Runchel C, Chai A, Basith S, et al. Signal integration by the $\mathrm{K} B$ protein pickle shapes Drosophila innate host defense. Cell Host Microbe. 2016;20(3):283-95.

63. Ratzka C, Gross R, Feldhaar H. Gene expression analysis of the endosymbiont-bearing midgut tissue during ontogeny of the carpenter ant Camponotus floridanus. J Insect Physiol. 2013;59(6):611-23.

64. Wang J, Wu Y, Yang G, Aksoy S. Interactions between mutualist Wigglesworthia and tsetse peptidoglycan recognition protein (PGRP-LB) 
influence trypanosome transmission. Proc Natl Acad Sci USA. 2009; 106(29):12133-8.

65. Wang J, Aksoy S. PGRP-LB is a maternally transmitted immune milk protein that influences symbiosis and parasitism in tsetse's offspring. Proc Natl Acad Sci U S A. 2012;109(26):10552-7.

66. Masson F, Moné Y, Vigneron A, Vallier A, Parisot N, Vincent-Monégat C, et al. Weevil endosymbiont dynamics is associated with a clamping of immunity. BMC Genomics. 2015;16(1):819.

67. Kaneko T, Yano T, Aggarwal K, Lim JH, Ueda K, Oshima Y, et al. PGRP-LC and PGRP-LE have essential yet distinct functions in the drosophila immune response to monomeric DAP-type peptidoglycan. Nat Immunol. 2006; (7):715-23.

68. Choe KM, Werner T, Stöven S, Hultmark D, Anderson KV. Requirement for a peptidoglycan recognition protein (PGRP) in relish activation and antibacterial immune responses in Drosophila. Science. 2002;296(5566):359-62.

69. Gottar M, Gobert V, Michel T, Belvin M, Duyk G, Hoffmann JA, et al. The Drosophila immune response against Gram-negative bacteria is mediated by a peptidoglycan recognition protein. Nature. 2002;416:640-4.

70. Kim D, Thairu MW, Hansen AK. Novel insights into insect-microbe interactionsrole of epigenomics and small RNAs. Front Plant Sci. 2016;7:1164.

71. Zhang $X$, Zheng $Y$, Jagadeeswaran $G$, Ren $R$, Sunkar $R$, Jiang $H$. Identification of conserved and novel microRNAs in Manduca sexta and their possible roles in the expression regulation of immunity-related genes. Insect Biochem Mol Biol. 2014;47:12-22.

72. Choi IK, Hyun S. Conserved microRNA miR-8 in fat body regulates innate immune homeostasis in Drosophila. Dev Comp Immunol. 2012;37(1):50-4.

73. Hussain M, Frentiu FD, Moreira LA, O'Neill SL, Asgari S. Wolbachia uses host microRNAs to manipulate host gene expression and facilitate colonization of the dengue vector Aedes Aegypti. Proc Natl Acad Sci USA. 2011;108(22):9250-5.

74. Nardon P. Obtention d'une souche aposymbiotique chez le charançon Sitophilus sasakii Tak: différentes méthodes d'obtention et comparaison avec la souche symbiotique d'origine. C R Acad Sci Paris. 1973;227D:981-4.

75. R Core Team. R: A language and environment for statistical computing. $R$ Foundation for Statistical Computing, Vienna, Austria. URL http://www.Rproject.org/. 2014;

\section{Submit your next manuscript to BioMed Central and we will help you at every step:}

- We accept pre-submission inquiries

- Our selector tool helps you to find the most relevant journal

- We provide round the clock customer support

- Convenient online submission

- Thorough peer review

- Inclusion in PubMed and all major indexing services

- Maximum visibility for your research

Submit your manuscript at www.biomedcentral.com/submit
Biomed Central 